\title{
Recalibrating the risk of hamstring strain injury (HSI): A 2020 systematic review and meta-analysis of risk factors for index and recurrent hamstring strain injury in sport
}

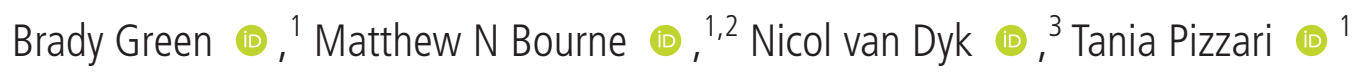

- Additional material is published online only. To view please visit the journal online (http://dx.doi.org/10.1136/ bjsports-2019-100983).

${ }^{1}$ La Trobe Sport and Exercise Medicine Research Centre, La Trobe University, Melbourne, Victoria, Australia ${ }^{2}$ School of Allied Health Sciences, Griffith University, Gold Coast Campus, Queensland, Australia ${ }^{3}$ High Performance Unit, Irish Rugby Football Union, Dublin, Ireland

Correspondence to Brady Green, La Trobe Sport and Exercise Medicine Research Centre, La Trobe University, Melbourne, VIC 3086, Australia; B.Green2@latrobe.edu.au

Accepted 28 February 2020 Published Online First 16 April 2020

\begin{abstract}
Objective To systematically review risk factors for hamstring strain injury (HSI).

Design Systematic review update.

Data sources Database searches: (1) inception to 2011

(original), and (2) 2011 to December 2018 (update).

Citation tracking, manual reference and ahead of press
\end{abstract} searches.

Eligibility criteria for selecting studies Studies presenting prospective data evaluating factors associated with the risk of index and/or recurrent HSI.

Method Search result screening and risk of bias assessment. A best evidence synthesis for each factor and meta-analysis, where possible, to determine the association with risk of HSI.

Results The 78 studies captured 8,319 total HSIs, including 967 recurrences, in 71,324 athletes. Older age (standardised mean difference $=1.6, p=0.002$ ), any history of $\mathrm{HSI}$ (risk ratio $(\mathrm{RR})=2.7, \mathrm{p}<0.001)$, a recent $\mathrm{HSI}(\mathrm{RR}=4.8$, $p<0.001)$, previous anterior cruciate ligament $(A C L)$ injury $(R R=1.7, p=0.002)$ and previous calf strain injury $(R R=1.5$, $p<0.001)$ were significant risk factors for HSI. From the best evidence synthesis, factors relating to sports performance and match play, running and hamstring strength were most consistently associated with HSI risk. The risk of recurrent $\mathrm{HSI}$ is best evaluated using clinical data and not the MRI characteristics of the index injury.

Summary/conclusion Older age and a history of HSI are the strongest risk factors for HSI. Future research may be directed towards exploring the interaction of risk factors and how these relationships fluctuate over time given the occurrence of index and recurrent HSI in sport is multifactorial.

\section{INTRODUCTION}

The hamstrings are involved in a host of athletic motions that include running, ${ }^{1-3}$ jumping $^{4}$ and kicking. ${ }^{5}$ Hamstring function is important to the performance of most sport-related activities, particularly when fast running is required. ${ }^{2-7}$ Injuries to the hamstring muscles compromise individual performance and team success in many sports. ${ }^{8-13}$ Awareness of risk factors for hamstring strain injury (HSI) is an important component of athlete load management, injury prevention and return to play decision-making post injury. ${ }^{14} 15$ Previous reviews of risk factors for injury have identified that older age and a history of HSI are commonly associated with a greater risk of future HSI. ${ }^{16-18}$
Prospective studies continue to examine a range of modifiable and non-modifiable factors to determine which are most associated with HSI. ${ }^{19-21}$ Hamstring strength can now be measured using novel field-based procedures, ${ }^{22}$ such as the Nordic hamstring exercise (NHE) test. ${ }^{23-25}$ The relationship between hamstring strength measured by these devices and HSI risk is not known. ${ }^{1626}$ In a 2018 systematic review, isokinetic strength testing did not accurately predict risk of HSI. ${ }^{26}$ Whether an athlete's training load, including various measures of running workload and match exposure, increase HSI risk is of interest. ${ }^{27-30}$

Given the significant body of new research, we updated our 2013 systematic review ${ }^{16}$ of risk factors for sport-related index and recurrent HSI. $^{31} 32$.

\section{METHOD}

Search strategy and selection of studies

A systematic search was carried out using Medline, CINAHL, Embase, AMED, AUSPORT, SportDiscus, PEDro and the Cochrane Library from 2011 to December 2018. Previous searches from the original systematic review captured studies published from database inception to $2011 .^{16}$ The studies included in the original review were included in this update. An identical search method was used, including databases searched. ${ }^{16}$ Keywords derived from the research question were used to structure the search and were mapped to medical subject headings where possible (online supplementary appendix 1). Citation tracking and manual reference list scanning were carried out. Ahead of press searching was performed using key sports medicine journals identified from database searches (British Journal of Sports Medicine, Scandinavian Journal of Medicine and Science in Sports, American Journal of Sports Medicine, Sports Medicine). Acquired references were imported and duplicates were removed (EndNote V.X3 software, Thomas Reuters, New York; USA). All reviewers (BG, MNB, NvD, TP) took part in applying selection criteria to prospective studies. Consensus was reached by discussion where required.

\section{Study selection criteria}

Participants/injury

Included studies investigated index (ie, a firsttime injury within the surveillance period) and/ or recurrent HSIs (ie, a second HSI following an index HSI) $)^{31} 32$ in athletic populations during sportrelated activities. All studies presented discrete data 
for HSI. Only HSIs were examined; studies examining tendinopathy, non-specific thigh injuries, hamstring origin avulsions and contusion-type pathologies were excluded.

\section{Risk factors for HSI}

Studies were required to present discrete data for one or more risk factors and their association with HSI. Intrinsic (eg, age, injury history, physical qualities) and extrinsic (eg, environment, stage of the season, competition schedule) factors were included. Studies reporting data that were not directly examined in relation to injury risk or the occurrence of HSI were excluded.

\section{Study type}

Systematic reviews and studies involving the analysis of prospectively collected data on non-modifiable factors were included. Intervention studies were excluded to limit potential confounding. All included studies involved human participants, were published in English and full-text versions were available. Conference abstracts and unpublished data were excluded.

\section{Data collection and analysis}

\section{Risk of bias assessment}

Three reviewers (BG, MNB, NvD) used a modified version of the Quality in Prognosis Studies (QUIPS) tool to assess the risk of bias of all studies that were not systematic reviews. Risk of bias assessment using the QUIPS has been previously described ${ }^{33} 34$ and has been utilised in recent HSI-related systematic reviews. ${ }^{263536}$ The QUIPS permits a systematic approach to best evidence synthesis described in detail later. Two of three reviewers were allocated to each study (BG, MNB, NvD). Discrepancies between authors in QUIPS scoring were reassessed and resolved by a third reviewer to reach consensus.

Six areas of assessment determined the overall risk of bias for each study: study participation, study attrition, prognostic factor measurement, outcome measurement, study confounding, and statistical analysis and reporting (online supplementary appendix 1). Each area has specific criteria that all studies are appraised against to identify whether it is a potential source of bias. Criteria are given a score of either 'yes' or 'no', and if for a single category there are less than $75 \%$ of 'yes' responses, it is deemed to be a 'high risk' of bias for that area of study design. 'Low risk' for an area is reached by scoring a 'yes' for $75 \%$ or more of the criteria for that single category. A study is then given an overall risk of bias according to the scores of each area. To be deemed as a 'low risk of bias' study, it must score a 'yes' for at least five categories. It must have also scored a 'yes' for the area relating to outcome measurement (item 4). Studies are otherwise classed as 'high risk of bias'.

\section{Data extraction}

Data were extracted with a focus on factors evaluated for their association with index and/or recurrent HSI. Raw data were extracted according to outcome measurement and the results reported. Reviewers extracted data relating to the key results, athletic population, length of tracking, and methods of HSI diagnosis and injury classification.

Data analysis and best evidence synthesis

Non-blinded reviewers (BG, TP) extracted data independently, including mean values, medians, standard deviations (SDs), risk ratios (RRs), odds ratios (ORs) and hazard ratios (HRs). For continuous data, the difference in the injured and uninjured group means were divided by the pooled SD to calculate standardised mean differences (SMDs) and their accompanying 95\% confidence intervals (CIs). ${ }^{37}$ The SMD indicates the magnitude of difference between injured and non-injured groups for a continuous variable. Where appropriate the RRs were recalculated from raw data provided. The reported ratios

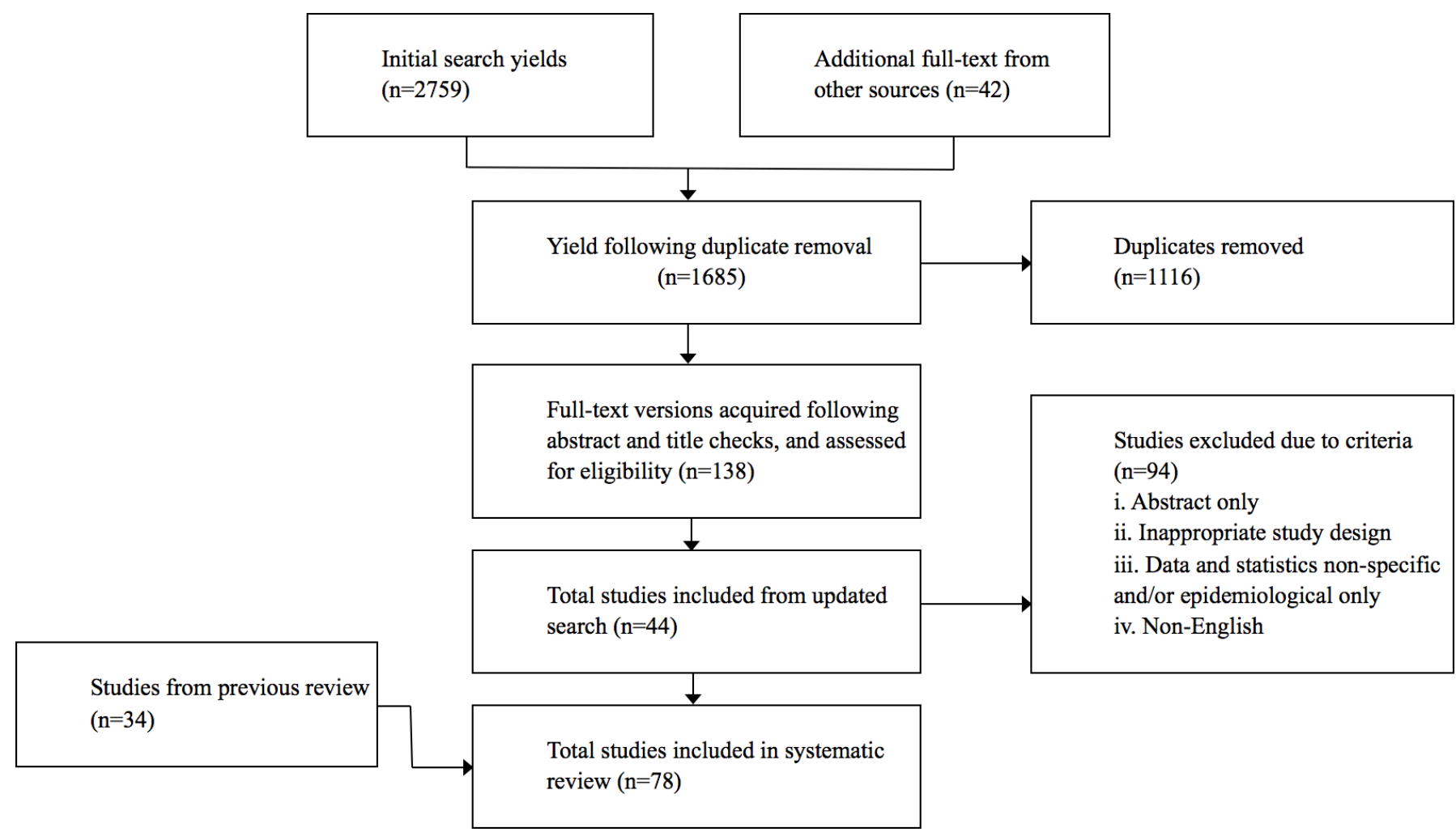

Figure 1 Flow diagram demonstrating study selection for the analysis of risk factors for index and recurrent hamstring strain injury. 
and the 95\% CI were used when the studies did not provide adequate frequency data. Comprehensive meta-analysis V.2.0 (Biostat, Englewood, New Jersey, USA) was used to perform meta-analyses from data provided in individual studies for the potential risk factors for HSI. A random effects model was used to better account for potential methodological or statistical heterogeneity. Compared to a fixed effects approach, a random effects model reduces the likelihood of a type two error by making it more difficult for a result to be determined as statistically significant. The random effects model offers more accurate and statistically safer information by generating wider CIs around pooled effect sizes. ${ }^{37}$ Heterogeneity was assessed using the $\mathrm{I}^{2}$ statistic. ${ }^{38}$ Effect sizes were interpreted as small $(0$ to 0.20$)$, moderate $(0.21$ to 0.5$)$ or large $(\geq 0.80)$. Statistical significance was set at $\mathrm{p}<0.05 .^{39}$

A best evidence synthesis was used to identify the level of evidence (LOE) and strength of association between each factor and HSI risk. The best evidence synthesis provided another source of information in conjunction with findings from the meta-analyses. It was used to clarify the relationship with HSI when heterogeneity or a paucity of raw data did not permit a meta-analysis to be performed. ${ }^{2635}{ }^{36}$ For each risk factor analysed the LOE is determined according to set criteria that includes information from the risk of bias assessment. ${ }^{40}{ }^{41}$ Listed below are the four hierarchical levels of evidence:

1. Strong evidence: Consistent results in two or more low risk of bias studies, with generally consistent findings in $\geq 75 \%$ of studies.

2. Moderate evidence: One low risk of bias study and one or more high risk of bias studies provide consistent findings, or consistent findings reported in two or more high risk of bias studies with consistent results in $\geq 75 \%$ studies.

3. Limited evidence: Single study findings from either a high risk or low risk of bias study.

4. Conflicting evidence: Multiple studies (of either high risk or low risk of bias) that do not provide consistent results, with consistent results in $<75 \%$ studies.

\section{RESULTS}

\section{Search results}

Initial searches yielded 2759 articles and there were an additional 42 articles from other sources (citation tracking, ahead of press searches, manual reference checking). This yield was reduced to 1685 following removal of duplicates. Screening of the titles and abstracts resulted in selection of 138 articles for analysis in full-text form, and 44 of these articles were determined to meet the requirements for inclusion. Once combined with the yield from the original systematic review, ${ }^{16}$ a final total of 78 studies were included (figure 1).

\section{Description of the included studies}

The most represented athletic populations were: football $(n=26)$, Australian Football $(n=21)$, and track and field $(n=8)$; in predominantly male cohorts from the elite level of competition (elite: 61\%, amateur: $23 \%$, mixed: $16 \%$ ), aged $16-37$ years. Study populations originated from the United Kingdom (UK), Australia, France, 'Europe', Norway, Iceland, Belgium, Brazil, Qatar, Japan, the United States of America (USA) and the Netherlands. Across all studies 8,319 total HSIs, including 967 confirmed recurrences, were captured among 71,324 subjects (online supplementary table 1).

\section{Overview of results of risk of bias assessment (QUIPS)}

A low risk of bias was found for 28 studies $(40 \%){ }^{12} 2023-252728$ 42-62 A high risk of bias was identified in 42 studies $(60 \%)^{19} 21222930$ 63-99 (table 1). Authors reached full agreement on risk of bias assessment (BG, MNB, NvD). The most common potential source of bias was 'study confounding variables' (item 5: 64.3\%), which was related to whether potential confounders were defined, identified and accounted for in the study design and analysis. Other sources of bias included study attrition (item 2: 35.7\%), study participation (item 1: 31.4\%), outcome measurement (item 4: 28.4\%), prognostic factor measurement (item 3: 25.6\%), statistical analysis and reporting (item 6: 18.3\%).(table 1 ) Systematic reviews ${ }^{18} 26100-105$ were not subject to the QUIPS tool.

\section{Overview of results from meta-analyses}

Twenty-one potential risk factors were evaluated using metaanalysis. From these results, the strongest risk factors for HSI were older age (figure 2), history of HSI, previous anterior cruciate ligament (ACL) injury and previous calf strain injury (figure 3). None of the 13 strength-related variables were significantly associated with risk of HSI (figure 4).

\section{Overview of results from the best evidence synthesis}

The best evidence synthesis included 179 factors and their association with index (129 factors) and/or recurrent (50 factors) HSI. Forty-nine factors demonstrated evidence for an association with increased risk of HSI (index: 41, recurrent: 8). One hundred and twelve factors demonstrated evidence for no association with increased risk of HSI (index: 73, recurrent: 39). Eighteen showed conflicting evidence of an unknown association with HSI (index: 15, recurrent: 3) (online supplementary appendix 2: tables 2-5).

\section{Risk factor evaluation according to key areas of risk Non-modifiable factors}

Older age was associated with a greater risk of HSI from meta-analysis of 19 studies $(\mathrm{SMD}=1.6,95 \% \mathrm{CI} 0.6$ to 2.6, $\mathrm{p}=0.002$ ). ${ }^{20} 2123-25274245465055-57606171739095$ (figure 2). A history of HSI (RR=2.7, p<0.001), ${ }^{23-25} 2747528588$ ACL injury $(\mathrm{RR}=1.7, \mathrm{p}=0.002),{ }^{23-25} 2730$ knee injury (LOE: moderate), ${ }^{46} 95$ calf strain injury $(\mathrm{RR}=1.5, \mathrm{p}<0.001)^{23-25} 3052$ and ankle ligament injury (LOE: limited) ${ }^{51}$ increased the risk of HSI; if the previous HSI occurred within the same season the risk was even greater (ie, recent history: $\mathrm{RR}=4.8, \mathrm{p}<0.001$ ) 30525985 (figure 3, online supplementary appendix 2: table 2). A history of quadriceps strain injury $23-2549$ and previous chronic groin pathology/'osteitis pubis ${ }^{23-25} 95$ did not increase the risk of HSI (LOE: strong) (online supplementary appendix 2: table 3).

\section{Architecture and structure}

Athlete (weight, body mass index) and muscle (biceps femoris; ${ }^{24}$ gluteus maximus, gluteus medius) ${ }^{74}$ size did not increase the risk of HSI (figure 2, online supplementary appendix 2: table 3), but biceps femoris fascicle length ${ }^{24}$ and hamstring muscle-tendon unit stiffness ${ }^{60}$ were associated with risk of index HSI (LOE: limited) (online supplementary appendix 2: table 2).

\section{Strength}

Reduced hamstring strength qualities, strength endurance (index: single leg hamstring bridge; ${ }^{46}$ recurrent: eccentric leg curl $^{21}$ ) and strength (hand held dynamometry; index: eccentric, ${ }^{22}$ isometric; ${ }^{22}$ recurrent: isometric ${ }^{44}$ ), were associated with 


\begin{tabular}{|c|c|c|c|c|c|c|c|}
\hline \multirow[b]{2}{*}{ Study } & \multicolumn{6}{|c|}{ Potential risk of bias item } & \multirow[b]{2}{*}{ Risk of bias } \\
\hline & 1 & 2 & 3 & 4 & 5 & 6 & \\
\hline Árnason et a $\left.\right|^{42}$ & + & + & + & + & + & + & Low \\
\hline Bengtsson et a/ ${ }^{63}$ & + & - & + & + & - & + & High \\
\hline Bennell et $a /^{65}$ & + & - & + & + & - & + & High \\
\hline Bennell et a $\left.\right|^{/ 4}$ & + & + & - & + & - & + & High \\
\hline Bourne et $a^{23}$ & + & - & + & + & + & + & Low \\
\hline Bradley and Portas ${ }^{66}$ & - & + & + & - & - & + & High \\
\hline Brooks et al ${ }^{12}$ & + & + & + & + & - & + & Low \\
\hline Brooks and Kemp ${ }^{67}$ & + & - & + & + & - & + & High \\
\hline Cameron et al ${ }^{68}$ & - & + & + & - & - & + & High \\
\hline Carling et $a l^{69}$ & - & + & - & + & - & + & High \\
\hline Christensen and Wiseman ${ }^{70}$ & - & - & - & - & - & - & High \\
\hline Croisier et al ${ }^{43}$ & + & + & + & + & - & + & Low \\
\hline Dauty et al $l^{11}$ & + & + & - & + & - & - & High \\
\hline De Vos et al ${ }^{44}$ & + & + & + & + & - & + & Low \\
\hline Duhig et $a^{28}$ & + & + & + & + & + & + & Low \\
\hline Elliott $e t a l^{72}$ & - & - & + & + & - & - & High \\
\hline Engebretsen et $a^{/ 45}$ & + & + & + & + & + & + & Low \\
\hline Fousekis et al $l^{73}$ & + & + & - & - & - & + & High \\
\hline Frannetovich-Smith et a ${ }^{14}$ & + & + & + & + & - & - & High \\
\hline Freckleton et $a^{46}$ & + & + & + & + & - & + & Low \\
\hline Gabbe et $a l^{76}$ & - & + & - & - & - & + & High \\
\hline Gabbe et $a{ }^{47}$ & + & + & + & + & - & + & Low \\
\hline Gabbe et $a l^{75}$ & - & - & + & + & - & + & High \\
\hline Gibbs et al ${ }^{77}$ & + & + & - & + & - & - & High \\
\hline Goossens et a ${ }^{22}$ & - & - & - & + & + & + & High \\
\hline Hägglund et a $\left.\right|^{48}$ & + & + & + & + & + & + & Low \\
\hline Hägglund et al/9 & + & + & + & + & - & + & Low \\
\hline Henderson et $a l^{50}$ & + & + & + & + & + & + & Low \\
\hline $\mid g u c h i$ et $\left.a\right|^{78}$ & + & + & + & - & - & + & High \\
\hline Koulouris et al ${ }^{79}$ & - & + & - & - & - & - & High \\
\hline Lawrence et a $\left.\right|^{30}$ & - & + & - & + & - & + & High \\
\hline Lee et $a l^{81}$ & - & - & + & + & + & + & High \\
\hline Malliaropoulos et $a l^{82}$ & + & + & - & - & - & - & High \\
\hline Malliaropoulos et $a l^{51}$ & + & + & + & + & + & + & Low \\
\hline Opar et $a /^{83}$ & + & + & + & - & - & + & High \\
\hline Opar et $a^{25}$ & + & + & + & + & + & + & Low \\
\hline Orchard et $a^{84}$ & + & - & + & + & - & + & High \\
\hline Orchard et $a^{52}$ & + & - & + & + & + & + & Low \\
\hline Orchard et a $\left.\right|^{29}$ & - & - & + & + & - & + & High \\
\hline Orchard et a $\beta^{30}$ & - & - & + & + & + & + & High \\
\hline Orchard et $a^{85}$ & - & + & + & + & - & + & High \\
\hline Pollock et $a l^{86}$ & - & + & + & + & + & - & High \\
\hline Reurink et $a l^{87}$ & - & + & + & - & - & + & High \\
\hline Roe et $a l^{88}$ & - & - & + & + & - & + & High \\
\hline Rolls and George ${ }^{89}$ & - & + & + & - & - & + & High \\
\hline Ruddy et $a l^{27}$ & + & + & + & + & + & + & Low \\
\hline Schuermans et al ${ }^{21}$ & + & - & - & + & - & - & High \\
\hline Schuermans et a $a^{90}$ & + & - & - & + & + & + & High \\
\hline Schuermans et a $a^{91}$ & + & - & + & - & - & + & High \\
\hline Schuermans et al92 & + & - & + & - & - & + & High \\
\hline Sugiura et $a l^{53}$ & + & + & - & + & + & + & Low \\
\hline Timmins et $a^{24}$ & + & + & + & + & + & + & Low \\
\hline van der Made et $a^{93}$ & - & - & + & + & + & + & High \\
\hline van der Made et $\left.a\right|^{54}$ & + & + & + & + & + & + & Low \\
\hline van Doormaal et al ${ }^{19}$ & + & - & + & - & + & + & High \\
\hline
\end{tabular}

Continued
Table 1 Continued

\begin{tabular}{|c|c|c|c|c|c|c|c|}
\hline \multirow[b]{2}{*}{ Study } & \multicolumn{6}{|c|}{ Potential risk of bias item } & \multirow[b]{2}{*}{ Risk of bias } \\
\hline & 1 & 2 & 3 & 4 & 5 & 6 & \\
\hline van Dyk et $a^{20}$ & + & + & + & + & + & + & Low \\
\hline van Dyk et $\left.a\right|^{55}$ & + & - & + & + & + & + & Low \\
\hline van Dyk et $\left.a\right|^{56}$ & + & + & + & + & + & + & Low \\
\hline van Dyk et $\left.a\right|^{57}$ & + & + & + & + & + & + & Low \\
\hline Venturelli et $a l^{94}$ & + & + & + & - & - & + & High \\
\hline Verrall et $a f^{58}$ & + & + & + & + & - & + & Low \\
\hline Verrall et $a l^{95}$ & + & + & + & - & - & + & High \\
\hline Warren et $a^{59}$ & + & + & + & + & - & + & Low \\
\hline Watsford et a ${ }^{60}$ & + & - & + & + & + & + & Low \\
\hline Witvrouw et a ${ }^{96}$ & - & - & - & - & - & - & High \\
\hline Woods et $a^{97}$ & + & - & - & - & - & - & High \\
\hline Yamada and Matsumoto ${ }^{98}$ & - & + & - & - & - & - & High \\
\hline Yamamoto et $a^{99}$ & - & - & - & - & - & - & High \\
\hline Yeung et $a^{61}$ & + & + & + & + & - & + & Low \\
\hline Zvijac et al ${ }^{62}$ & + & + & + & + & - & + & Low \\
\hline
\end{tabular}

1, study participation, 2, study attrition, 3, prognostic factor measurement, 4 , outcome measurement, 5, study confounding variables, 6 , statistical analysis and reporting.

an increased risk of HSI (LOE: limited) (online supplementary appendix 2: tables 2 and 5). Eccentric hamstring strength during the NHE was not associated with risk of HSI from the metaanalysis $\left(\mathrm{SMD}_{\text {absolute }}=-0.31,95 \% \mathrm{CI}-0.97\right.$ to $0.4, \mathrm{p}=0.13$; $\mathrm{SMD}_{\text {relative }}=-0.34,95 \% \mathrm{CI}-1.1$ to $\left.0.4, \mathrm{p}=0.14\right) ;^{23-25} 55$ the best evidence synthesis identified conflicting evidence of an unknown association (figure 4, online supplementary appendix 2: table 4). In 11 meta-analyses isokinetic testing was unrelated to HSI risk (figure 4).

\section{Power and ballistic function}

Reduced single leg hop for distance ${ }^{22}$ and the percentage difference between non-countermovement jump and countermovement jump ${ }^{94}$ were associated with risk of index HSI (LOE: limited) (online supplementary appendix 2: table 2). Other countermovement jump measures were not associated with index HSI, such as height (LOE: strong) 4250788494 and power output (LOE: moderate) ${ }^{42} 78$ (online supplementary appendix 2: table 3).

Flexibility, mobility and range of motion

No factor related to flexibility, mobility and range of motion showed a clear relationship with risk of index HSI, including common hamstring tests: passive knee extension (LOE: strong), ${ }^{4245568991}$ active knee extension (LOE: strong), ${ }^{475675768991}$ passive straight leg raise (LOE: strong) 5061758996 and slump (LOE: moderate) 47 $^{4576}$ (online supplementary appendix 2: table 3). A greater active knee extension deficit just after return to play increased the risk of recurrent HSI (LOE: limited) ${ }^{44}$ (online supplementary appendix 2: table 5). The relationships between reduced hip extension (modified Thomas test) 47757691 and ankle dorsiflexion (lunge) 4647567576 and risk of index HSI were conflicting (online supplementary appendix 2: table 4).

\section{Electromyography and motor control}

Reduced trunk muscle (cluster of: internal oblique, external oblique, thoracic erector spinae, lumbar erector spinae) electromyographic (EMG) activity during the backswing phase of sprinting (LOE: limited) ${ }^{90}$ and increased gluteus medius 
Age 20,21,23-25,27,42,45,46,50,55-57, $60,61,71,73,90,95$
Height $20,23-25,27,42,45,55-57,60,61,71,73$, $90,91,95,99$

Weight $20,23-25,27,42,45,55-57,60,61,71,73$ $90,91,95,99$

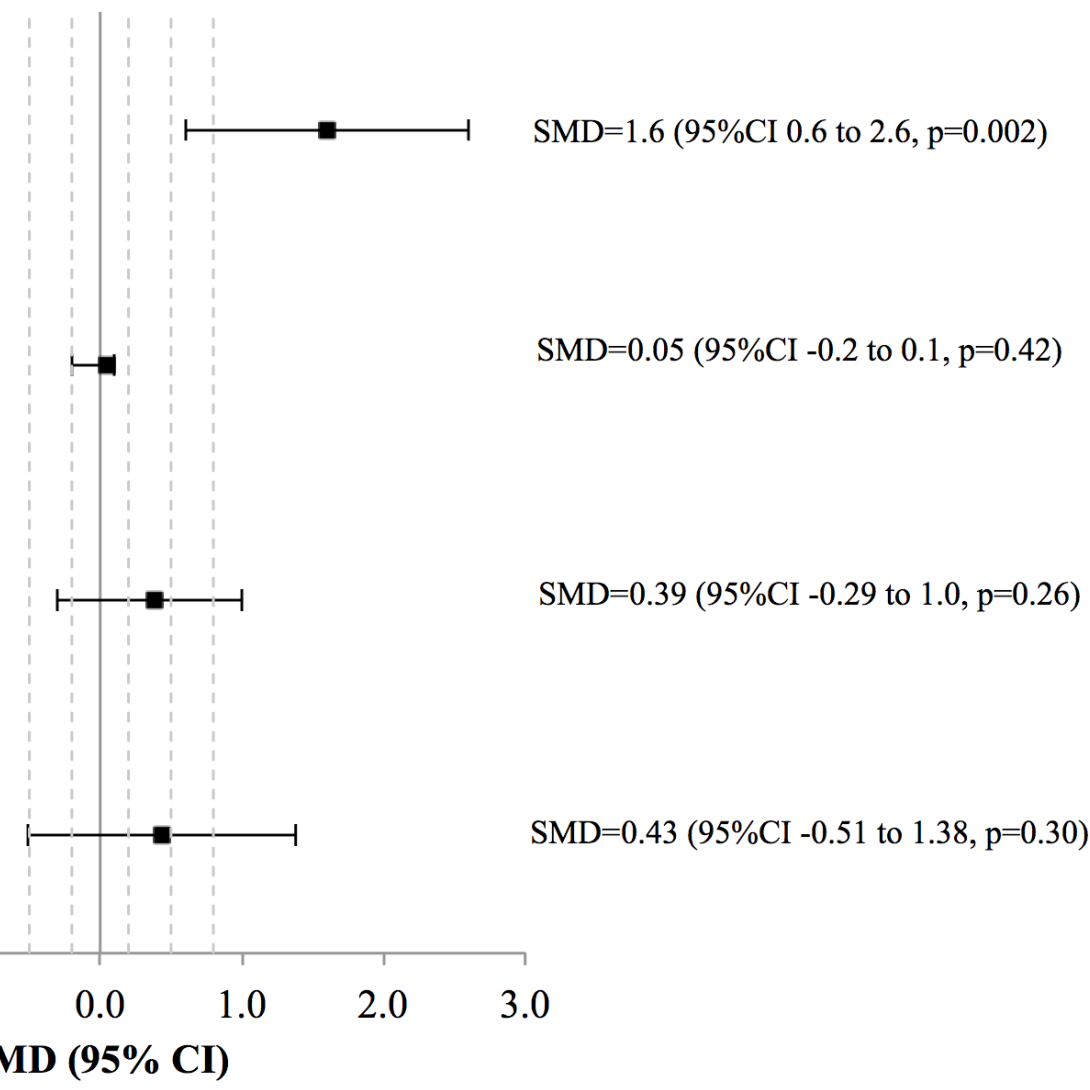

Figure 2 Meta-analysis for age, height, weight and body mass index. SMD, standardised mean difference.

EMG activity during running ( $12 \mathrm{~km} /$ hour, $15 \mathrm{~km} /$ hour) (LOE: limited) ${ }^{74}$ were associated with risk of index HSI (online supplementary appendix 2: table 2). There were conflicting findings for gluteus maximus EMG activity while sprinting and running at a range of submaximal speeds ${ }^{74} 90$ (online supplementary appendix 2: table 4). Trunk and hamstring motor control were associated with index HSI in three studies: muscle recruitment pattern during prone hip extension (LOE: limited), ${ }^{91}$ dominance of biceps femoris recruitment during a fatiguing eccentric leg curl (LOE: limited) ${ }^{21}$ and hamstring movement discrimination (LOE: limited) ${ }^{68}$ (online supplementary appendix 2: table 2).

Running-based measurements

Increases in high-speed running exposure were associated with a greater risk of index $\mathrm{HSI}^{2728}$ (online supplementary appendix 2: table 2). Sprinting kinematics were also associated with index

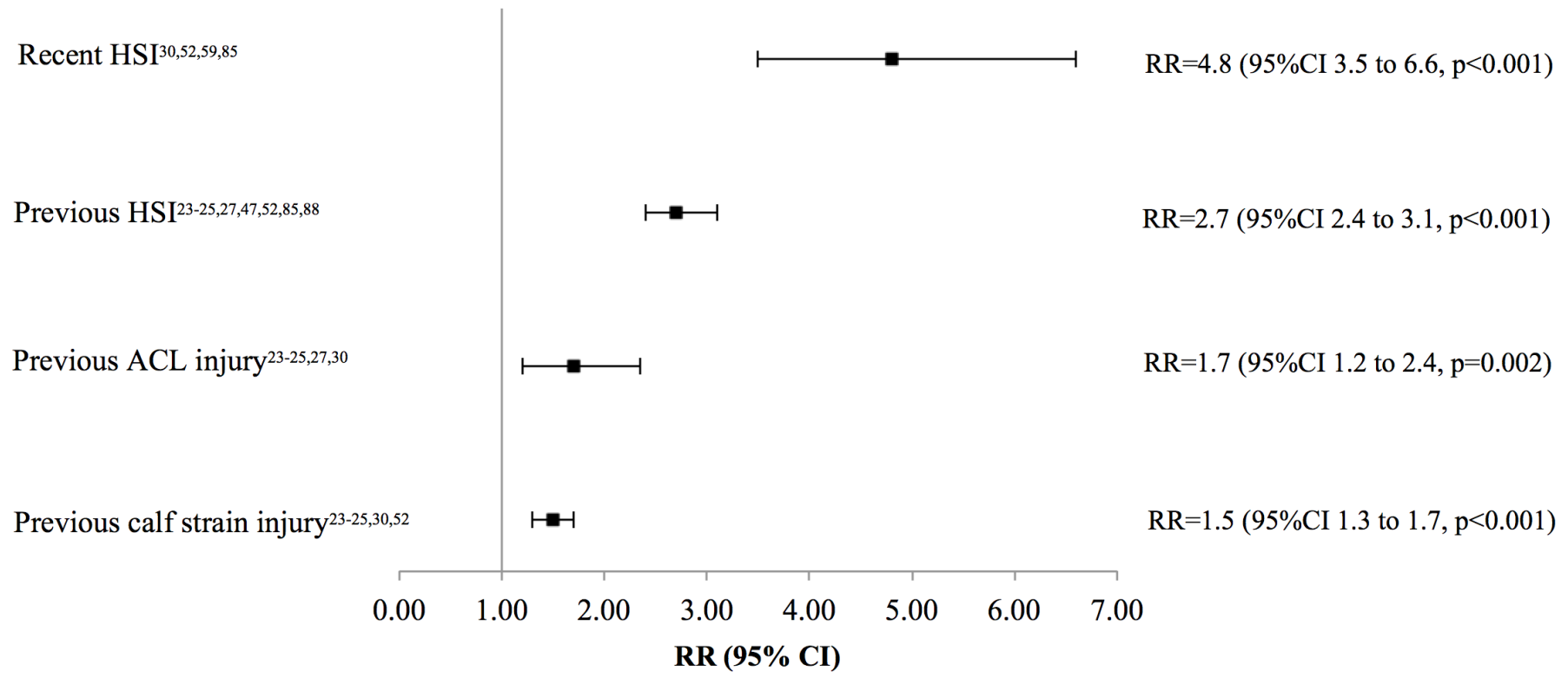

Figure 3 Meta-analysis for injury history: hamstring strain injury (HSI), ACL injury and calf strain injury. RR, risk ratio. 
$\mathrm{NHE}(\mathrm{N})^{23-25,55}$

NHE(N.kg) $)^{23-25,55}$

Abs. concHS60\% $\mathbf{s}^{20,45,55,62,64,73,81}$

Rel. concHS $60^{\circ} / \mathrm{s}^{20,50,55,64,68,81,84}$

Abs. eccHS60\% $/ \mathrm{s}^{20,55,73}$

Rel. eccHS60 $/ \mathrm{s}^{20,55,64}$

Abs. concHS $300^{\circ} / \mathbf{s}^{20,50,55,62,73}$

Rel. concHS300\% $\mathrm{s}^{20,50,55,84}$

Conv. HS:Qu60\%/ $\mathrm{s}^{50,62,64,68,71,81,84,98}$

Abs. concQu60\% $/ \mathrm{s}^{20,50,55,62,64,81}$

Rel. concQu60\%/ $20,50,55,64,68,81,84$

Abs. concQu $300^{\circ} / \mathrm{s}^{20,50,55,62}$

Rel. concQu300\%/ $20,50,55,84$
$\mathrm{SMD}=-0.31(95 \% \mathrm{CI}-0.97$ to $0.4, \mathrm{p}=0.13)$

$\mathrm{SMD}=-0.34(95 \% \mathrm{CI}-1.1$ to $0.4, \mathrm{p}=0.14)$

$\mathrm{SMD}=-0.11(95 \% \mathrm{CI}-0.4$ to $0.12, \mathrm{p}=0.25)$

$\mathrm{SMD}=-0.19(95 \% \mathrm{CI}-0.6$ to $0.2, \mathrm{p}=0.24)$

$\mathrm{SMD}=-0.08(95 \% \mathrm{CI}-0.24$ to $0.08, \mathrm{p}=0.33)$

$\mathrm{SMD}=-0.05(95 \% \mathrm{CI}-0.28$ to $0.19, \mathrm{p}=0.69)$

$\mathrm{SMD}=-0.011(95 \% \mathrm{CI}-0.13$ to $0.11, \mathrm{p}=0.85)$

$\mathrm{SMD}=-0.008(95 \% \mathrm{CI}-0.21$ to $0.2, \mathrm{p}=0.94)$

$\mathrm{SMD}=-0.22(95 \% \mathrm{CI}-0.7$ to $0.24, \mathrm{p}=0.26)$

$\mathrm{SMD}=-0.04(95 \% \mathrm{CI}-0.24$ to $0.2, \mathrm{p}=0.65)$

$\mathrm{SMD}=0.1(95 \% \mathrm{CI}-0.24$ to $0.4, \mathrm{p}=0.64)$

$\mathrm{SMD}=0.07$ (95\%CI -0.01 to $0.2, \mathrm{p}=0.27)$

$\mathrm{SMD}=0.12(95 \% \mathrm{CI}-0.01$ to $0.25, \mathrm{p}=0.08)$
HSI risk in cases of increased thoracic side-bending during front swing (LOE: limited) ${ }^{92}$ and increased anterior pelvic tilt during backswing (LOE: limited) ${ }^{92}$ (online supplementary appendix 2: table 2). Aerobic ( $\left.\mathrm{VO}_{2} \max \right)$ (LOE: moderate), ${ }^{42}{ }^{84}$ intermittent running (YoYo) (LOE: moderate), ${ }^{50} 94$ sprinting (40 m sprint characteristics) (LOE: moderate) $)^{4584}$ and agility (LOE: limited) $)^{50}$ test results were not associated with risk of index HSI (online supplementary appendix 2: table 3).

Sports performance and match play

Playing position impacted the risk of index HSI in football (LOE: strong), $1920454955-57719497$ American football (LOE: moderate), ${ }^{62} 72$ rugby (LOE: moderate), ${ }^{12} 67$ Gaelic football $\left(\right.$ LOE: limited) ${ }^{88}$ and cricket (LOE: limited) ${ }^{85}$ (online supplementary appendix 2: table 2). Positions that can have larger running demands resulted in a greater risk of index HSI in football (midfielders, defenders and forwards vs goalkeepers), ${ }^{49} 56$ American football (receivers, defensive backs, running backs vs linemen) ${ }^{72}$ and cricket (fast bowlers vs spin bowlers). ${ }^{85}$ Reduced between match recovery and/or increased schedule congestion $^{296369}$ and the level of competition ${ }^{458397}$ showed conflicting relationships with HSI risk (online supplementary appendix 2: table 4).

Clinical and imaging examination of the index $\mathrm{HSI}$

Clinical examination findings of the index HSI at baseline (the number of previous HSIs; ${ }^{44}$ reduced strength endurance $)^{21}$ and just after return to play (strength; range of motion; tenderness to palpation $)^{44}$ were associated with greater risk of recurrent HSI (LOE: limited) (online supplementary appendix 2: table 5). None of the MRI findings of the index HSI were clearly associated with greater risk of recurrent HSI whether taken at baseline or return to play, including conflicting evidence of an unknown association for intratendinous injury/intramuscular tendon disruption ${ }^{54105}$ (online supplementary appendix 2: table 5).

\section{Environmental factors}

International travel prior to a cricket match was associated with HSI (LOE: limited). ${ }^{85}$ Other environmental factors were unrelated to risk of HSI (online supplementary appendix 2: tables 2 and 3 ).

\section{DISCUSSION}

We investigated 179 potential risk factors in a data set of 8,319 HSIs, including 967 recurrences, in over 71,000 athletes. Older age and previous injury were the strongest risk factors for HSI from meta-analysis. Athletes who have any history of HSI are 2.7 times more likely to sustain a HSI than those without, and they are at an even greater risk if the previous HSI occurred in the same season ( $\approx 5$ times). The influence of these non-modifiable factors was not consistent across studies, highlighting the potential modulation of risk by other factors such as the physical characteristics of the athlete (eg, strength qualities), ${ }^{22} 2546106$ exposure to load (eg, highspeed $^{27} 28$ and match ${ }^{29} 30$ running workload) and mechanical function when performing sport-related activities (eg, running kinematics). ${ }^{92107}$ In the best evidence synthesis, factors related to sports performance and match play, running and strength were most consistently associated with HSI.

\section{Modifiable risk factors}

Strength and flexibility qualities were the most investigated modifiable risk factors for HSI. While baseline strength deficits were associated with a greater risk of HSI in a number of studies, ${ }^{21} 224446$ flexibility, mobility and range of motion provided limited value as stand-alone risk factors. Strength and flexibility qualities change over time and fluctuate in response to exposure (ie, fatigue). ${ }^{14} 108$ It may not be valid to use data from a single occasion of baseline assessment to prospectively evaluate associations with subsequent HSI. Testing procedures may be better implemented as part of ongoing monitoring rather than 
baseline screening ${ }^{16}$ and when employed regularly as part of the clinical management of an index HSI to avoid a recurrence. ${ }^{108} 109$ This could be especially relevant for susceptible athletes, such as those who are older, have a history of HSI and a hamstring strength deficit. ${ }^{24} 25110$

Running exposure is another modifiable risk factor for HSI. $^{27} 28$ The risk of subsequent HSI is elevated in athletes exposed to greater high-speed running loads, especially with sudden increases (ie, within the previous 7-14 days). ${ }^{272}$ These athletes may be predisposed to HSI due to the fatigue and eccentrically induced muscle damage associated with fast running activities. ${ }^{111}$ Graduated exposure may also be advantageous for resilience to injury mechanisms such as sprinting. ${ }^{112} 113$ A balance must be found between inducing positive adaptations that are protective against HSI and excessive exposure that increases susceptibility to HSI. ${ }^{113114}$

\section{Non-modifiable risk factors}

Athletes who are older and have an injury history are often at greater risk of a future injury. ${ }^{10} 164952115$ 'Old' is difficult to define, as age can influence HSI risk in athletes as young as 24 years. ${ }^{52}$ Age could impact HSI risk because it correlates with exposure: over time (ie, with older age) athletes are exposed to greater mechanical loads and the likelihood of encountering injury mechanisms increases. Small differences in age likely represent large differences in exposure in elite sport. Agerelated physical changes may also predispose older athletes to $\mathrm{HSI}^{116}$ by affecting structural (eg, altered architecture, ${ }^{117}{ }^{118}$ fibre type populations, ${ }^{119}{ }^{120}$ cross-sectional area, ${ }^{120} 121$ stiffness ${ }^{122}$ ) and neurological (eg, denervation of high-threshold motor units $^{123-125}$ ) qualities.

Previous muscle injury can also result in structural (reduced biceps femoris fascicle length, ${ }^{118}$ atrophy, ${ }^{126}$ scar tissue ${ }^{127}$ ) and neurological (reduced voluntary activation ${ }^{128}$ ) maladaptation within the injured muscle. This may explain reduced hamstring strength ${ }^{129130}$ and a shift towards peak knee flexor torque generation at shorter muscle-tendon unit lengths ${ }^{131}$ following a HSI. Persistent deficits may reduce the ability of the hamstrings to tolerate high degrees of stress and strain, contributing to an elevated risk of recurrence.

A novel finding is that athletes with a history of ACL injury have a $70 \%$ increase in risk of HSI, and a previous calf strain injury increases the risk by $50 \%$. The mechanisms responsible for the increased risk following ACL injury are unclear, but reduced proprioception, strength deficits and altered gait could contribute. ${ }^{132-134}$ Susceptibility to HSI following an ACL reconstruction may also be associated with ongoing hamstring deficits due to the graft used. ${ }^{135} 136$ Athletes may be more likely to sustain a HSI following a calf strain injury because the hamstrings become less conditioned to tolerate injury mechanisms and high-speed running workloads after a period of reduced exposure. ${ }^{28}$ This highlights the importance of holistic rehabilitation and greater consideration for the risk of subsequent HSI when athletes return to play from these injuries.

\section{Recurrent HSI}

Clinical data about the history of HSI and persistent hamstring deficits best evaluate risk of recurrent HSI. Strength deficits, reduced hamstring flexibility and palpation tenderness at return to play may indicate an increased risk of recurrent HSI. MRI descriptors of the index HSI at baseline and return to play do not accurately predict risk of recurrence.
What is already known

Older age and a history of hamstring strain injury (HSI) are strong risk factors for HSI.

\section{What are the new findings}

- Older age and injury history (HSI, ACL injury, calf strain injury) are associated with an increased risk of subsequent HSI.

- Key areas to evaluate athletes for information about risk of $\mathrm{HSI}$ are sports performance and match play, hamstring strength, and running.

- Clinical examination findings best evaluate the risk of recurrent HSI.

- Future research should consider examining the interactions between risk factors for $\mathrm{HSI}$, along with how these relationships fluctuate over time, such as over the course of a competition season.

\section{Implications/future directions}

Awareness of risk factors may be useful for athlete management to mitigate HSI risk. The identification of modifiable risk factors is an important component of injury prevention models. ${ }^{137} 138$ Identifying single risk factors provides some direction for clinicians, but fails to account for the complex and fluctuating interactions between risk factors. ${ }^{139}$ The interactions between potential risk factors for HSI is accounted for in some investigations, ${ }^{24} 140$ but further research is needed to fully understand these relationships and how they may influence injury risk. ${ }^{139}$ Such investigations may be especially important to guide clinical practice since HSIs (index or recurrent) unlikely occur because of any isolated factor. ${ }^{109} 110129$

\section{LIMITATIONS}

As with any systematic review or meta-analysis, the strength of these results relies on the quality of the studies included. A lack of consistency in injury definitions and variable study methods (see online supplementary table 1), as well as limited consideration between injury types (eg, index vs recurrent HSI) and mechanisms (acute vs gradual onset injuries), ${ }^{16-18}$ are limitations of the included studies. Distinctions between index and recurrent HSI are not always clearly described. Even when this is defined, the classification of a recurrent HSI often relied on participant memory, subject to recall bias. Some recurrences may have been erroneously recorded as an index HSI despite the presence of an injury history. Given the exclusion of intervention studies, data derived from the control groups in these studies are not included here. Another shortcoming of the available evidence is that the sample size and number of HSIs are often too small to meet the methodological requirements when investigating these relationships. ${ }^{141}$ Publication and language biases are other potential limitations of this review.

\section{CONCLUSION}

Older age, and a history of HSI, ACL injury and calf strain injury were significant risk factors for HSI. Factors related to sports performance and match play, running and hamstring strength are likely important for evaluating the risk profile of athletes, which reflects the multifactorial nature of index and recurrent HSIs. 
Correction notice This article has been corrected since it published Online First. The title has been amended.

Twitter Brady Green @BradyDGreen, Matthew N Bourne @mbourne5, Nicolvan Dyk @NicolvanDyk and Tania Pizzari @DrTaniaPizzari

Contributors All authors made equal contributions to the work. All authors provided permission for the submission and publication of this version of the review.

Funding The authors have not declared a specific grant for this research from any funding agency in the public, commercial or not-for-profit sectors.

\section{Competing interests None declared.}

Patient consent for publication Not required.

Provenance and peer review Not commissioned; externally peer reviewed.

\section{ORCID iDs}

Brady Green http://orcid.org/0000-0003-1135-0033

Matthew N Bourne http://orcid.org/0000-0002-3374-4669

Nicol van Dyk http://orcid.org/0000-0002-0724-5997

Tania Pizzari http://orcid.org/0000-0002-8804-0095

\section{REFERENCES}

1 Schache AG, Blanch PD, Dorn TW, et al. Effect of running speed on lower limb joint kinetics. Med Sci Sports Exerc 2011;43:1260-71.

2 Dorn TW, Schache AG, Pandy MG. Muscular strategy shift in human running: dependence of running speed on hip and ankle muscle performance. J Exp Biol 2012;215:1944-56

3 Schache AG, Dorn TW, Williams GP, et al. Lower-Limb muscular strategies for increasing running speed. J Orthop Sports Phys Ther 2014;44:813-24.

4 Walsh M, Boling MC, McGrath M, et al. Lower extremity muscle activation and knee flexion during a jump-landing task. J Athl Train 2012;47:406-13.

5 Rahnama N, Lees A, Bambaecichi E. A comparison of muscle strength and flexibility between the preferred and non-preferred leg in English soccer players. Ergonomics 2005;48:1568-75.

6 Duhig SJ, Williams MD, Minett GM, et al. Drop punt kicking induces eccentric knee flexor weakness associated with reductions in hamstring electromyographic activity. J Sci Med Sport 2017;20:595-9.

7 Schache AG, Dorn TW, Blanch PD, et al. Mechanics of the human hamstring muscles during sprinting. Med Sci Sports Exerc 2012;44:647-58.

8 Hägglund M, Waldén M, Magnusson $\mathrm{H}$, et al. Injuries affect team performance negatively in professional football: an 11-year follow-up of the UEFA Champions League injury study. Br J Sports Med 2013;47:738-42.

9 Hickey J, Shield AJ, Williams MD, et al. The financial cost of hamstring strain injuries in the Australian Football League. Br J Sports Med 2014;48:729-30.

10 Ekstrand J, Hägglund M, Waldén M. Epidemiology of muscle injuries in professional football (soccer). Am J Sports Med 2011;39:1226-32.

11 Australian Football League. 2018 AFL injury report, 2019: 1-19.

12 Brooks JH, Fuller CW, Kemp SP, et al. Incidence, risk, and prevention of hamstring muscle injuries in professional rugby union. Am J Sports Med 2006;34:1297-306.

13 Dalton SL, Kerr ZY, Dompier TP. Epidemiology of Hamstring Strains in 25 NCAA Sports in the 2009-2010 to 2013-2014 Academic Years. Am J Sports Med 2015;43:2671-9.

14 Wollin M, Thorborg K, Pizzari T. Monitoring the effect of football match congestion on hamstring strength and lower limb flexibility: Potential for secondary injury prevention? Phys Ther Sport 2018;29:14-18.

15 Ardern CL, Glasgow P, Schneiders A, et al. 2016 Consensus statement on return to sport from the First World Congress in Sports Physical Therapy, Bern. Br I Sports Med 2016;50:853-64.

16 Freckleton G, Pizzari T. Risk factors for hamstring muscle strain injury in sport: a systematic review and meta-analysis. Br J Sports Med 2013;47:351-8.

17 Opar DA, Williams MD, Shield AJ. Hamstring strain injuries: factors that lead to injury and re-injury. Sports Med 2012;42:209-26.

18 de Visser HM, Reijman M, Heijboer MP, et al. Risk factors of recurrent hamstring injuries: a systematic review. Br I Sports Med 2012:46:124-30.

19 van Doormaal MC, van der Horst N, Backx FJ, et al. No Relationship Between Hamstring Flexibility and Hamstring Injuries in Male Amateur Soccer Players: A Prospective Study. Am I Sports Med 2017;45:121-6.

20 van Dyk N, Bahr R, Whiteley R, et al. Hamstring and Quadriceps Isokinetic Strength Deficits Are Weak Risk Factors for Hamstring Strain Injuries: A 4-Year Cohort Study. Am J Sports Med 2016;44:1789-95.

21 Schuermans J, Van Tiggelan D, Danneels L, et al. Susceptibility to Hamstring Injuries in Soccer: A Prospective Study Using Muscel Functional Magnetic Resonance Imaging. Am J Sports Med 2016;44:1276-85.

22 Goossens L, Witvrouw E, Vanden Bossche L, et al. Lower eccentric hamstring strength and single leg hop for distance predict hamstring injury in PETE students. Eur J Sport Sci 2015;15:436-42.
23 Bourne MN, Opar DA, Williams MD, et al. Eccentric Knee Flexor Strength and Risk of Hamstring Injuries in Rugby Union: A Prospective Study. Am I Sports Med 2015;43:2663-70.

24 Timmins RG, Bourne MN, Shield AJ, et al. Short biceps femoris fascicles and eccentric knee flexor weakness increase the risk of hamstring injury in elite football (soccer): a prospective cohort study. Br J Sports Med 2016;50:1524-35.

25 Opar DA, Williams MD, Timmins RG, et al. Eccentric hamstring strength and hamstring injury risk in Australian footballers. Med Sci Sports Exerc 2015;47:857-65.

26 Green B, Bourne MN, Pizzari T. Isokinetic strength assessment offers limited predictive validity for detecting risk of future hamstring strain in sport: a systematic review and meta-analysis. Br J Sports Med 2018;52:329-36.

27 Ruddy JD, Pollard CW, Timmins RG, et al. Running exposure is associated with the risk of hamstring strain injury in elite Australian footballers. Br I Sports Med 2018; 52:919-28.

28 Duhig S, Shield AJ, Opar D, et al. Effect of high-speed running on hamstring strain injury risk. Br J Sports Med 2016;50:1536-40.

29 Orchard JW, Seward H, Orchard JJ, et al. The speed-fatigue trade off in hamstring aetiology: Analysis of 2011 AFL injury data. Sport Health 2012;30:53-7.

30 Orchard JW, Driscoll T, Seward H, et al. Relationship between interchange usage and risk of hamstring injuries in the Australian Football League. J Sci Med Sport 2012;15:201-6

31 Finch CF, Cook J. Categorising sports injuries in epidemiological studies: the subsequent injury categorisation (SIC) model to address multiple, recurrent and exacerbation of injuries. Br I Sports Med 2014;48:1276-80.

32 Hamilton GM, Meeuwisse WH, Emery CA, et al. Subsequent injury definition, classification, and consequence. Clin J Sport Med 2011;21:508-14.

33 Hayden JA, Côté P, Bombardier C. Evaluation of the quality of prognosis studies in systematic reviews. Ann Intern Med 2006;144:427-37.

34 Hayden JA, van der Windt DA, Cartwright JL, et al. Assessing bias in studies of prognostic factors. Ann Intern Med 2013;158:280-6.

35 Schut L, Wangensteen A, Maaskant J, et al. Can Clinical Evaluation Predict Return to Sport after Acute Hamstring Injuries? A Systematic Review. Sports Med 2017:47:1123-44.

36 Reurink G, Goudswaard GJ, Tol JL, et al. Therapeutic interventions for acute hamstring injuries: a systematic review. Br J Sports Med 2012;46:103-9.

37 Cooper H, Hedges V. The Handbook of research synthesis. New York: Russel Sage Foundation, 1994.

38 Higgins JPTet al. Measuring inconsistency in meta-analyses. BMJ 2003;327:557-60.

39 Cohen J. Statistical power analysis for the behavioural sciences. New York: Russel Sage Academic, 1988.

40 Slavin RE. Best evidence synthesis: an intelligent alternative to meta-analysis. J Clin Epidemiol 1995;48:9-18.

41 van Tulder M, Furlan A, Bombardier C, et al. Updated method guidelines for systematic reviews in the cochrane collaboration back review group. Spine (Phila Pa 1976) 2003:28:1290-9.

42 Arnason A, Sigurdsson SB, Gudmundsson A, et al. Risk factors for injuries in football. Am J Sports Med 2004;32:5S-16S.

43 Croisier JL, Ganteaume S, Binet J, et al. Strength imbalances and prevention of hamstring injury in professional soccer players: a prospective cohort study. Am J Sports Med 2008;36:1469-75.

44 De Vos RJ, Reurink G, Goudswaard GJ, et al. Clinical findings just after return to play predict hamstring re-injury, but baseline MRI findings do not. Br I Sports Med 2014:48:1377-84.

45 Engebretsen AH, Myklebust G, Holme I, et al. Intrinsic risk factors for hamstring injuries among male soccer players: a prospective cohort study. Am I Sports Med 2010:38:1147-53.

46 Freckleton G, Cook J, Pizzari T. The predictive validity of a single leg bridge test for hamstring injuries in Australian Rules Football Players. Br I Sports Med 2014;48:713-7

47 Gabbe BJ, Bennell KL, Finch CF, et al. Predictors of hamstring injury at the elite level of Australian football. Scand J Med Sci Sports 2006;16:7-13.

48 Hägglund $M$, Waldén $M$, Ekstrand J. Previous injury as a risk factor for injury in elite football: a prospective study over two consecutive seasons. Br I Sports Med 2006;40:767-72.

49 Hägglund $M$, Waldén $M$, Ekstrand J. Risk factors for lower extremity muscle injury in professional soccer: the UEFA Injury Study. Am J Sports Med 2013;41:327-35.

50 Henderson G, Barnes CA, Portas MD. Factors associated with increased propensity for hamstring injury in English premier League soccer players. J Sci Med Sport 2010;13:397-402.

51 Malliaropoulos N, Bikos G, Meke M, et al. Higher frequency of hamstring injuries in elite track and field athletes who had a previous injury to the ankle - a 17 years observational cohort study. J Foot Ankle Res 2018;11:1-8.

52 Orchard JW. Intrinsic and extrinsic risk factors for muscle strains in Australian football. Am J Sports Med 2001;29:300-3.

53 Sugiura Y, Saito T, Sakuraba K, et al. Strength deficits identified with concentric action of the hip extensors and eccentric action of the hamstrings predispose to hamstring injury in elite sprinters. J Orthop Sports Phys Ther 2008;38:457-64. 
54 van der Made AD, Almusa E, Reurink G, et al. Intramuscular tendon injury is not associated with an increased hamstring reinjury rate within 12 months after return to play. Br J Sports Med 2018;52:1261-6.

55 van Dyk N, Bahr R, Burnett AF, et al. A comprehensive strength testing protocol offers no clinical value in predicting risk of hamstring injury: a prospective cohort study of 413 professional football players. Br J Sports Med 2017;51:1695-702.

56 van Dyk N, Farooq A, Bahr R, et al. Hamstring and Ankle Flexibility Deficits Are Weak Risk Factors for Hamstring Injury in Professional Soccer Players: A Prospective Cohort Study of 438 Players Including 78 Injuries. Am J Sports Med 2018;46:2203-10.

57 van Dyk N, Bahr R, Burnett AF, et al. No association between rate of torque development and onset of muscle activity with increased risk of hamstring injury in elite football. Scand J Med Sci Sports 2018:28:2153-63.

58 Verrall GM, Slavotinek JP, Barnes PG, et al. Assessment of physical examination and magnetic resonance imaging findings of hamstring injury as predictors for recurrent injury. J Orthop Sports Phys Ther 2006;36:215-24.

59 Warren P, Gabbe BJ, Schneider-Kolsky M, et al. Clinical predictors of time to return to competition and of recurrence following hamstring strain in elite Australian footballers. Br J Sports Med 2010;44:415-9.

60 Watsford ML, Murphy AJ, McLachlan KA, et al. A prospective study of the relationship between lower body stiffness and hamstring injury in professional Australian rules footballers. Am J Sports Med 2010;38:2058-64.

61 Yeung SS, Suen AMY, Yeung EW. A prospective cohort study of hamstring injuries in competitive sprinters: preseason muscle imbalance as a possible risk factor. $\mathrm{Br} J$ Sports Med 2009;43:589-94.

62 Zvijac JE, Toriscelli TA, Merrick S, et al. Isokinetic concentric quadriceps and hamstring strength variables from the NFL Scouting Combine are not predictive of hamstring injury in first-year professional football players. Am J Sports Med 2013:41:1511-8.

63 Bengtsson H, Ekstrand J, Hägglund M. Muscle injury rates in professional football increase with fixture congestion: an 11-year follow-up of the UEFA Champions League injury study. Br J Sports Med 2013;47:743-7.

64 Bennell $\mathrm{K}$, Wajswelner $\mathrm{H}$, Lew $\mathrm{P}$, et al. Isokinetic strength testing does not predict hamstring injury in Australian Rules footballers. Br J Sports Med 1998;32:309-14.

65 Bennell K, Tully E, Harvey N. Does the toe-touch test predict hamstring injury in Australian Rules footballers? Aust J Physiother 1999;45:103-9.

66 Bradley PS, Portas MD. The relationship between preseason range of motion and muscle strain injury in elite soccer players. J Strength Cond Res 2007;21:1155-9.

67 Brooks JH, Kemp SP. Injury-prevention priorities according to playing position in professional rugby union players. Br J Sports Med 2011;45:765-75.

68 Cameron M, Adams R, Maher C. Motor control and strength as predictors of hamstring injury in elite players of Australian football. Phys Ther Sport 2003;4:159-66.

69 Carling C, McCall A, Le Gall F, et al. The impact of short periods of match congestion on injury risk and patterns in an elite football club. Br J Sports Med 2016;50:764-8.

70 Christensen C, Wiseman D. Strength, the common variable in hamstring strain. J Ath Train 1972:7:36-40.

71 Dauty M, Menu P, Fouasson-Chailloux A. Cutoffs of isokinetic strength ratio and hamstring strain prediction in professional soccer players. Scand J Med Sci Sports 2018;28:276-81

72 Elliott MC, Zarins B, Powell JW, et al. Hamstring muscle strains in professional football players: a 10-year review. Am J Sports Med 2011;39:843-50.

73 Fousekis K, Tsepis E, Poulmedis P, et al. Intrinsic risk factors of non-contact quadriceps and hamstring strains in soccer: a prospective study of 100 professional players. Br J Sports Med 2011;45:709-14.

74 Franettovich Smith MM, Bonacci J, Mendis MD, et al. Gluteus medius activation during running is a risk factor for season hamstring injuries in elite footballers. J Sci Med Sport 2017:20:159-63.

75 Gabbe BJ, Finch CF, Bennell KL, et al. Risk factors for hamstring injuries in community level Australian football. Br J Sports Med 2005;39:106-10.

76 Gabbe BJ, Bennell KL, Finch CF. Why are older Australian football players at greater risk of hamstring injury? J Sci Med Sport 2006;9:327-33.

77 Gibbs NJ, Cross TM, Cameron M, et al. The accuracy of MRI in predicting recovery and recurrence of acute grade one hamstring muscle strains within the same season in Australian Rules football players. I Sci Med Sport 2004;7:248-58.

78 Iguchi J, Watanabe Y, Kimura M, et al. Risk Factors for Injury Among Japanese Collegiate Players of American Football Based on Performance Test Results. J Strength Cond Res 2016;30:3405-11.

79 Koulouris $\mathrm{G}$, Connell DA, Brukner $\mathrm{P}$, et al. Magnetic resonance imaging parameters for assessing risk of recurrent hamstring injuries in elite athletes. Am J Sports Med 2007:35:1500-6.

80 Lawrence DW, Comper P, Hutchison MG. Influence of Extrinsic Risk Factors on National Football League Injury Rates. Orthop J Sports Med 2016;4:232596711663922-9.

81 Lee JWY, Mok K-M, Chan HCK, et al. Eccentric hamstring strength deficit and poor hamstring-to-quadriceps ratio are risk factors for hamstring strain injury in football: a prospective study of 146 professional players. J Sci Med Sport 2018;21:789-93.

82 Malliaropoulos N, Isinkaye T, Tsitas K, et al. Reinjury after acute posterior thigh muscle injuries in elite track and field athletes. Am J Sports Med 2011;39:304-10.
83 Opar DA, Drezner J, Shield A, et al. Acute hamstring strain injury in track-and-field athletes: A 3-year observational study at the Penn Relay Carnival. Scand J Med Sci Sports 2014;24:e254-9

84 Orchard J, Marsden J, Lord S, et al. Preseason hamstring muscle weakness associated with hamstring muscle injury in Australian footballers. Am J Sports Med 1997;25:81-5.

85 Orchard JW, Kountouris A, Sims K. Risk factors for hamstring injuries in Australian male professional cricket players. J Sport Health Sci 2017:6:271-4

86 Pollock N, Patel A, Chakraverty J, et al. Time to return to full training is delayed and recurrence rate is higher in intratendinous (' $c$ ') acute hamstring injury in elite track and field athletes: clinical application of the British Athletics Muscle Injury Classification. Br J Sports Med 2016:50:305-10.

87 Reurink G, Almusa E, Goudswaard GJ, et al. No association between fibrosis on magnetic resonance imaging at return to play and hamstring reinjury risk. Am J Sports Med 2015:43:1228-34.

88 Roe M, Murphy JC, Gissane C, et al. Hamstring injuries in elite Gaelic football: an 8year investigation to identify injury rates, time-loss patterns and players at increased risk. Br J Sports Med 2018;52:982-8.

89 Rolls A, George K. The relationship between hamstring muscle injuries and hamstring muscle length in young elite footballers. Phys Ther Sport 2004; $5: 179-87$

90 Schuermans J, Danneels L, Van Tiggelen D, et al. Proximal Neuromuscular Control Protects Against Hamstring Injuries in Male Soccer Players: A Prospective Study With Electromyography Time-Series Analysis During Maximal Sprinting. Am J Sports Med 2017:45:1315-25

91 Schuermans J, Van Tiggelen D, Witvrouw E. Prone Hip Extension Muscle Recruitment is Associated with Hamstring Injury Risk in Amateur Soccer. Int J Sports Med 2017;38:696-706.

92 Schuermans J, Van Tiggelen D, Palmans T, et al. Deviating running kinematics and hamstring injury susceptibility in male soccer players: Cause or consequence? Gait Posture 2017; 57:270-7.

93 van der Made AD, Almusa E, Whiteley R, et al. Intramuscular tendon involvement on MRI has limited value for predicting time to return to play following acute hamstring injury. Br J Sports Med 2018;52:83-8

94 Venturelli M, Schena F, Zanolla L, et al. Injury risk factors in young soccer players detected by a multivariate survival model. J Sci Med Sport 2011;14:293-8.

95 Verrall GM, Slavotinek JP, Barnes PG, et al. Clinical risk factors for hamstring muscle strain injury: a prospective study with correlation of injury by magnetic resonance imaging. Br J Sports Med 2001:35:435-9.

96 Witvrouw E, Danneels L, Asselman P, et al. Muscle flexibility as a risk factor for developing muscle injuries in male professional soccer players. A prospective study. Am J Sports Med 2003:31:41-6.

97 Woods C, Hawkins RD, Maltby S, et al. The Football Association Medical Research Programme: an audit of injuries in professional football--analysis of hamstring injuries. Br J Sports Med 2004;38:36-41

98 Yamada M, Mastumoto D. The Reaction Time of Mental Rotation Predicts Strain in Rugby Players. J Phys Ther Sci 2009;21:177-81.

99 Yamamoto T. Relationship between hamstring strains and leg muscle strength. A follow-up study of collegiate track and field athletes. J Sports Med Phys Fitness 1993:33:194-9.

100 Emery CA. Does decreased muscle strength cause acute muscle strain injury in sport? A systematic review of the evidence. Phys Ther Rev 1999:4:141-51.

101 Foreman TK, Addy T, Baker S, et al. Prospective studies into the causation of hamstring injuries in sport: A systematic review. Phys Ther Sport 2006; 7:101-9.

102 Olivier B, Taljaard T, Burger E, et al. Which Extrinsic and Intrinsic Factors are Associated with Non-Contact Injuries in Adult Cricket Fast Bowlers? Sports Med 2016:46:79-101.

103 Prior M, Guerin M, Grimmer K. An evidence-based approach to hamstring strain injury: a systematic review of the literature. Sports Health 2009;1:154-64.

104 van Beijsterveldt AMC, van de Port IGL, Vereijken AJ, et al. Risk Factors for Hamstring Injuries in Male Soccer Players: A Systematic Review of Prospective Studies. Scand J Med Sci Sports 2013:23:253-62.

105 van Heumen M, Tol JL, de Vos R-J, et al. The prognostic value of MRI in determining reinjury risk following acute hamstring injury: a systematic review. $\mathrm{Br} J$ Sports Med 2017;51:1355-63.

106 Suchomel TJ, Nimphius S, Stone MH. The Importance of Muscular Strength in Athletic Performance. Sports Med 2016;46:1419-49.

107 Bertelsen ML, Hulme A, Petersen J, et al. A framework for the etiology of runningrelated injuries. Scand J Med Sci Sports 2017;27:1170-80.

108 Whiteley R, van Dyk N, Wangensteen A, et al. Clinical implications from daily physiotherapy examination of 131 acute hamstring injuries and their association with running speed and rehabilitation progression. Br J Sports Med 2018:52:303-10

109 Mendiguchia J, Martinez-Ruiz E, Edouard P, et al. A Multifactorial, Criteria-based Progressive Algorithm for Hamstring Injury Treatment. Med Sci Sports Exerc 2017;49:1482-92. 
110 Bourne MN, Timmins RG, Opar DA, et al. An Evidence-Based Framework for Strengthening Exercises to Prevent Hamstring Injury. Sports Med 2018;48:251-67.

111 Howatson G, Milak A. Exercise-Induced muscle damage following a bout of sport specific repeated sprints. J Strength Cond Res 2009;23:2419-24.

112 Edouard P, Mendiguchia J, Guex K. Sprinting: a potential vaccine for hamstring injury? . SPSR, 2019: 48. 1-2.

113 Malone S, Roe M, Doran DA, et al. High chronic training loads and exposure to bouts of maximal velocity running reduce injury risk in elite Gaelic football. J Sci Med Sport 2017;20:250-4.

114 Buckthorpe M, Wright S, Bruce-Low S, et al. Recommendations for hamstring injury prevention in elite football: translating research into practice. Br J Sports Med 2019:53:449-56.

115 Green B, Pizzari T. Calf muscle strain injuries in sport: a systematic review of risk factors for injury. Br J Sports Med 2017;51:1189-94.

116 Orchard JW, Farhart P, Leopold C. Lumbar spine region pathology and hamstring and calf injuries in athletes: is there a connection? Br J Sports Med 2004;38:502-4.

117 Lieber RL, Fridén J. Functional and clinical significance of skeletal muscle architecture. Muscle Nerve 2000;23:1647-66.

118 Timmins RG, Shield AJ, Williams MD, et al. Architectural adaptations of muscle to training and injury: a narrative review outlining the contributions by fascicle length, pennation angle and muscle thickness. Br J Sports Med 2016;50:1467-72.

119 Faulkner JA, Larkin LM, Claflin DR, et al. Age-related changes in the structure and function of skeletal muscles. Clin Exp Pharmacol Physiol 2007;34:1091-6.

120 Lexell J. Human aging, muscle mass, and fiber type composition. J Gerontol A Biol Sci Med Sci 1995;50 Spec No:11-16.

121 Faulkner JA, Davis CS, Mendias CL, et al. The aging of elite male athletes: agerelated changes in performance and skeletal muscle structure and function. Clin J Sport Med 2008;18:501-7.

122 Narici MV, Maffulli N, Maganaris CN. Ageing of human muscles and tendons. Disabil Rehabil 2008:30:1548-54.

123 Roos MR, Rice CL, Vandervoort AA. Age-related changes in motor unit function. Muscle Nerve 1997;20:679-90.

124 Doherty TJ, Vandervoort AA, Brown WF. Effects of ageing on the motor unit: a brief review. Can J Appl Physiol 1993;18:331-58.

125 Webber SC, Porter MM, Gardiner PF. Modeling age-related neuromuscular changes in humans. Appl Physiol Nutr Metab 2009;34:732-44.

126 Sanfilippo JL, Silder A, Sherry MA, et al. Hamstring strength and morphology progression after return to sport from injury. Med Sci Sports Exerc 2013;45:448-54.
127 Silder A, Heiderscheit BC, Thelen DG, et al. MR observations of long-term musculotendon remodeling following a hamstring strain injury. Skeletal Radiol 2008;37:1101-9.

128 Fyfe JJ, Opar DA, Williams MD, et al. The role of neuromuscular inhibition in hamstring strain injury recurrence. J Electromyogr Kinesiol 2013;23:523-30.

129 Charlton PC, Raysmith B, Wollin M, et al. Knee flexion not hip extension strength is persistently reduced following hamstring strain injury in Australian Football athletes: Implications for Periodic Health Examinations. J Sci Med Sport 2018;21:999-1003.

130 Croisier JL, Forthomme B, Namurois MH, et al. Hamstring muscle strain recurrence and strength performance disorders. Am J Sports Med 2002;30:199-203.

131 Sole G, Milosavljevic S, Nicholson HD, et al. Selective strength loss and decreased muscle activity in hamstring injury. J Orthop Sports Phys Ther 2011;41:354-63.

132 Katayama M, Higuchi $\mathrm{H}$, Kimura M, et al. Proprioception and performance after anterior cruciate ligament rupture. Int Orthop 2004;28:278-81.

133 Abourezk MN, Ithurburn MP, McNally MP, et al. Hamstring Strength Asymmetry at 3 Years After Anterior Cruciate Ligament Reconstruction Alters Knee Mechanics During Gait and Jogging. Am J Sports Med 2017:45:97-105.

134 Tashman S, Collon D, Anderson K, et al. Abnormal rotational knee motion during running after anterior cruciate ligament reconstruction. Am J Sports Med 2004;32:975-83.

135 Bourne MN, Bruder AM, Mentiplay BF, et al. Eccentric knee flexor weakness in elite female footballers 1-10 years following anterior cruciate ligament reconstruction. Phys Ther Sport 2019;37:144-9.

136 Messer DJ, Shield AJ, Williams MD, et al. Hamstring muscle activation and morphology are significantly altered 1-6years after anterior cruciate ligament reconstruction with semitendinosus graft. Knee Surg Sports Traumatol Arthrosc 2020;28:733-41.

137 van Mechelen W, Hlobil H, Incidence HC. Incidence, severity, aetiology and prevention of sports injuries. A review of concepts. Sports Med 1992;14:82-99.

138 Finch C. A new framework for research leading to sports injury prevention. J Sci Med Sport 2006;9:3-10.

139 Bittencourt NFN, Meeuwisse WH, Mendonça LD, et al. Complex systems approach for sports injuries: moving from risk factor identification to injury pattern recognition-narrative review and new concept. Br J Sports Med 2016;50:1309-14.

140 Ruddy JD, Shield AJ, Maniar N, et al. Predictive Modeling of Hamstring Strain Injuries in Elite Australian Footballers. Med Sci Sports Exerc 2018;50:906-14.

141 Bahr R, Holme I. Risk factors for sports injuries--a methodological approach. Br J Sports Med 2003;37:384-92. 